\title{
Synthesis of new
}

\section{spiro pyrido[3',2':4,5]thieno[3,2-d]pyrimidines}

\author{
Vyacheslav S. Muraviev1, Darya Yu. Lukina1, \\ Victor V. Dotsenko1,2*, Vladimir D. Strelkov ${ }^{1}$
}

${ }^{1}$ Kuban State University, 149 Stavropolskaya str, Krasnodar, 350040 Russia e-mail:victor_dotsenko@bigmir.net

${ }^{2}$ ChemEx Lab, Vladimir Dal' Lugansk National University, 20A/7 Molodezhny, Lugansk, 91034 Russia

${ }^{3}$ All-Russian Research Institute of Biological Plant Protection, Laboratory of plant growth regulators, 350039 Krasnodar, Russian Federation

\section{Abstract}

A library of new spiro pyrido[3',2':4,5]thieno[3,2-d]pyrimidines was synthesized by reaction of 3-aminothieno[2,3-b]pyridine-2-carboxamides with ninhydrin. The optimal reaction conditions and mechanism are discussed.

\section{Keywords}

spiro compoinds, indane-1,2,3-trione, thieno[2,3-b]pyridines, pyrido[3',2':4,5]thieno[3,2-d]pyrimidines

The chemistry of thieno[2,3-b]pyridines is one of most interesting directions in the chemistry of heterocyclic compounds at the present time. Thienopyridines attract considerable interest because of their great practical usefulness, primarily, due to their various biological activities. Thienopyridines have attracted considerable attention, reflected in a number of reviews. Thieno[2,3-b]pyridines were reported as antiviral, anti-cancer, antibiotic agents they could be used in agriculture as insecticides, plant growth regulators, antidotes for herbicide 2,4-D. Thus, the synthesis of thieno[2,3-b]pyridines as well as their ring condensed analogs is of interest.

Here we wish to report the synthesis of a small library of new spiro pyrido[3',2':4,5] thieno[3,2-d]pyrimidines by reaction of 3 -aminothieno[2,3b]pyridine-2-carboxamides with ninhydrin. Starting 3-aminothieno[2,3b]pyridine-2-carboxamides 2 were prepared by the known method [1] 
starting from 3-cyanopyridine-2(1H)-thiones 1 and 2-chloroacetanilides. The structure of compounds 2 was confirmed by spectral data.

First, we have prepared Guareschi-Thorpe 3-cyano-2-pyridones by reaction of 1,3-diketones with cyanoacetamide. The pyridones were converted to 2-chloronicotinonitriles by treatment with $\mathrm{POCl}_{3}$ [1]. The prepared 2-chloronicotinonitriles were reacted with thiourea to give 3cyanopyridine-2(1H)-thiones 1 [2].

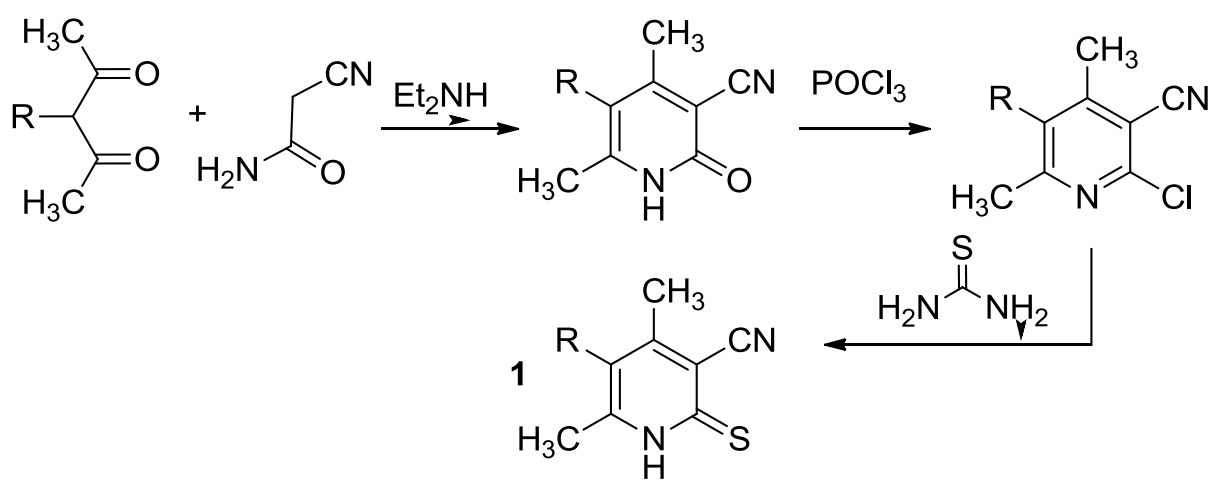

$\mathrm{R}=\mathrm{H}$, alkyl

We also prepared 4,6-diaryl-3-cyanopyridine-2(1H)-thiones by reaction of malononitrile with chalcones, followed by the treatment of $\delta$-keto dinitrile formed with sulphur in the presence of an organic base [3].

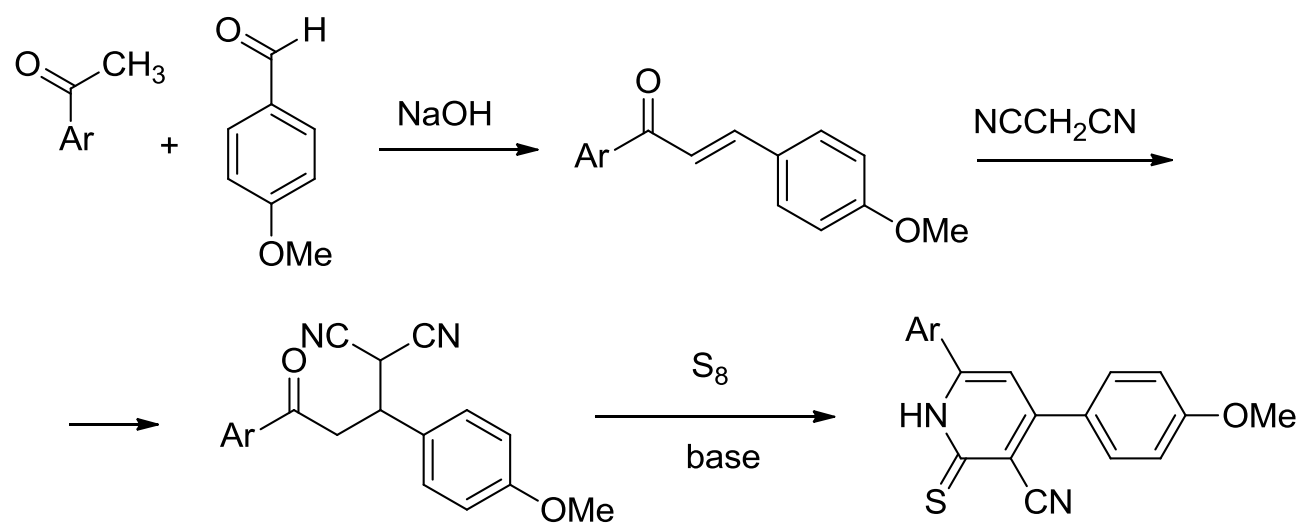

Next, we used one-pot Thorpe-Ziegler approach to prepare 3aminothieno[2,3-b]pyridine-2-carboxamides 2 . The reaction of thiones $\mathbf{1}$ with 2-chloroacetanilides in hot DMF in the presence of $25 \%$ excess of $\mathrm{NaOH}$ afforded desired thienopyridines 2 . The ${ }^{1} \mathrm{H}$ NMR spectrum of one of the thieno[2,3-b]pyridine-2-carboxamides is shown in Fig.1 

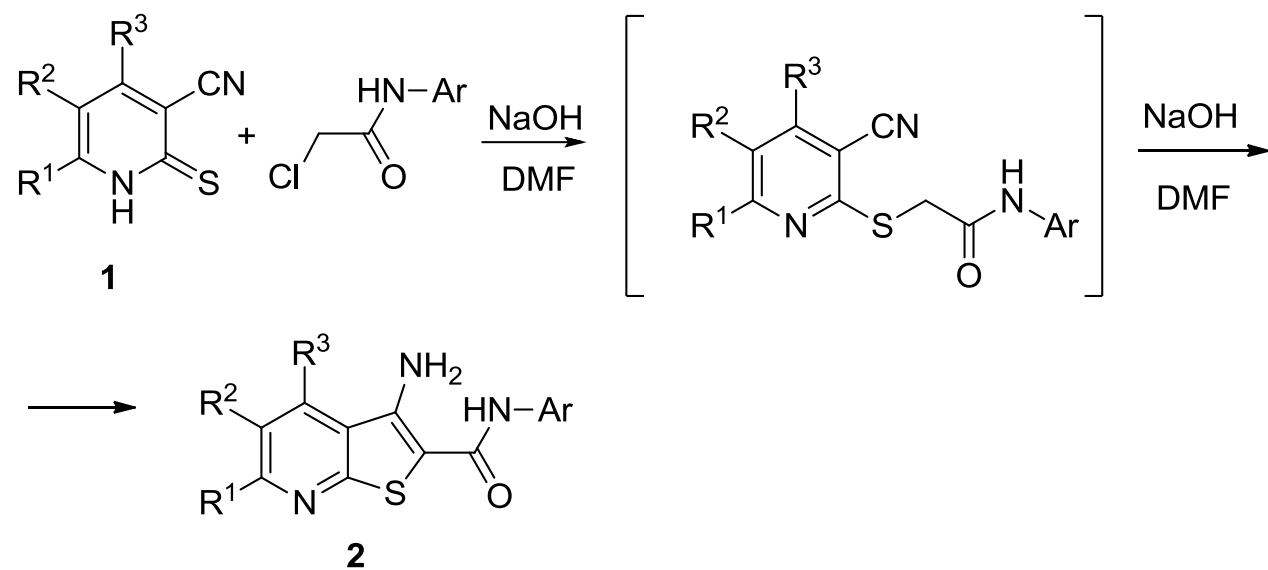

Fig.1. ${ }^{1} \mathrm{H}$ NMR spectrum of compound $2\left(\mathrm{R}^{1}=\mathrm{R}^{3}=\mathrm{Me}, \mathrm{R}^{2}=\mathrm{H}, \mathrm{Ar}=2-\mathrm{MeC}_{6} \mathrm{H}_{4}\right)$.
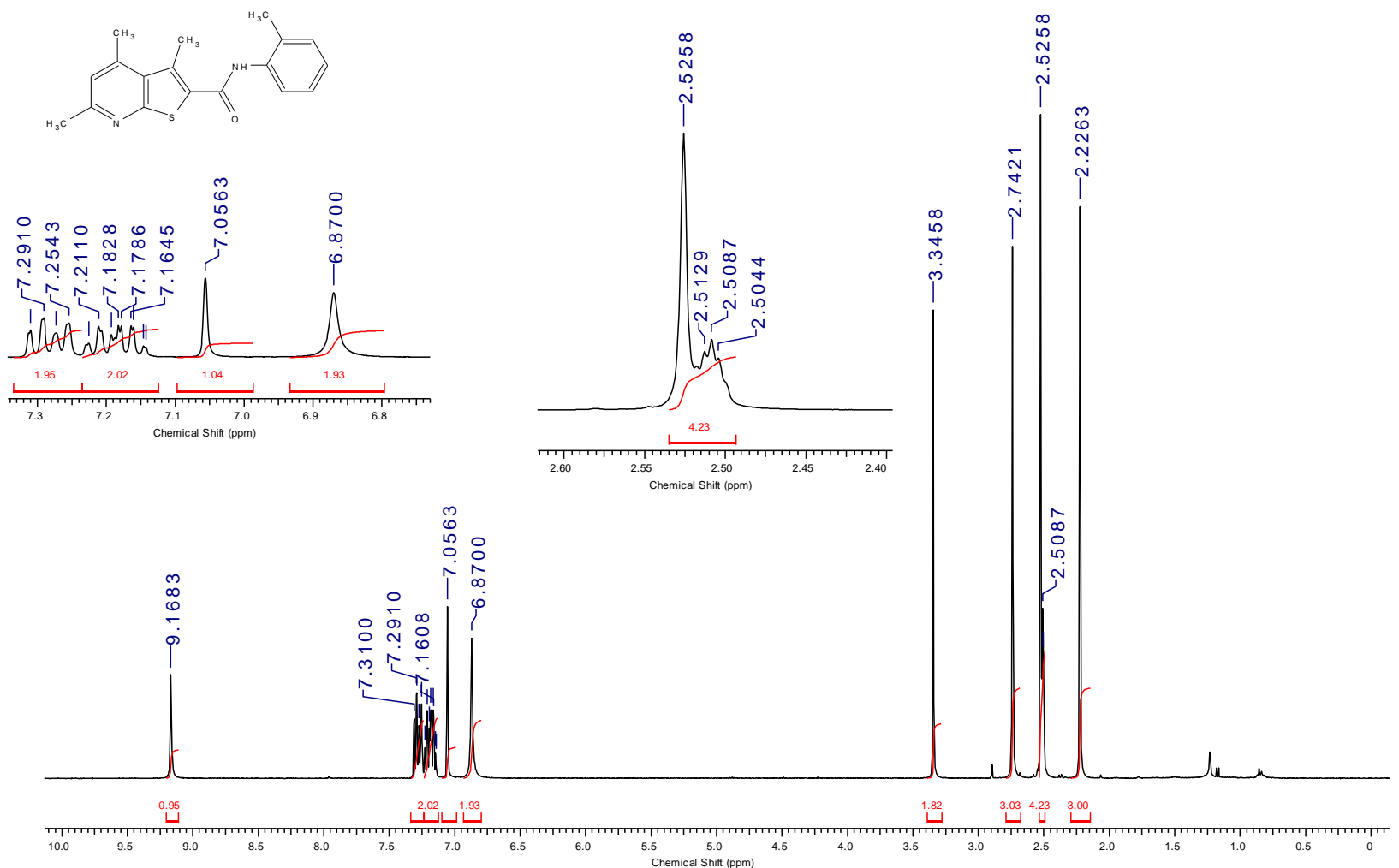

Finally, 3-aminothieno[2,3-b]pyridine-2-carboxamides 2 were reacted with ninhydrin. The conditions and the scope of the reaction were carefully studied. We found that the solvent of choice is $\mathrm{AcOH}$, and the best catalysts were found to be strong acids such as $\mathrm{H}_{2} \mathrm{SO}_{4}$ and $\mathrm{H}_{3} \mathrm{PO}_{4}$. A small library of about 20 new spiro pyrido[3',2':4,5]thieno[3,2-d]pyrimidines $\mathbf{3}$ was synthesized by reaction of amides 2 with ninhydrin. The ${ }^{1} \mathrm{H}$ NMR spectrum of one of the spiro products is shown in Fig.2. 


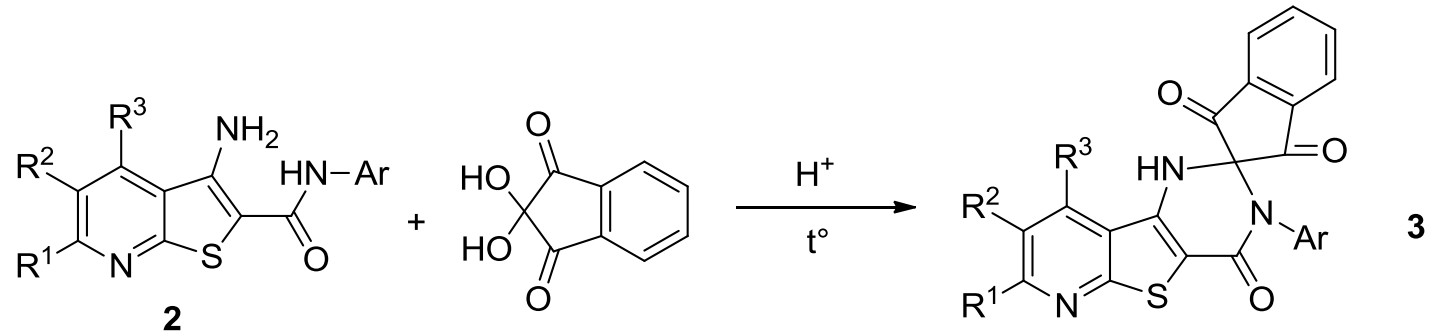

Fig. 2. ${ }^{1} \mathrm{H}$ NMR spectrum of compound $3\left(\mathrm{R}^{1}=\mathrm{R}^{3}=\mathrm{Me}, \mathrm{R}^{2}=\mathrm{H}, \mathrm{Ar}=\mathrm{Ph}\right)$.

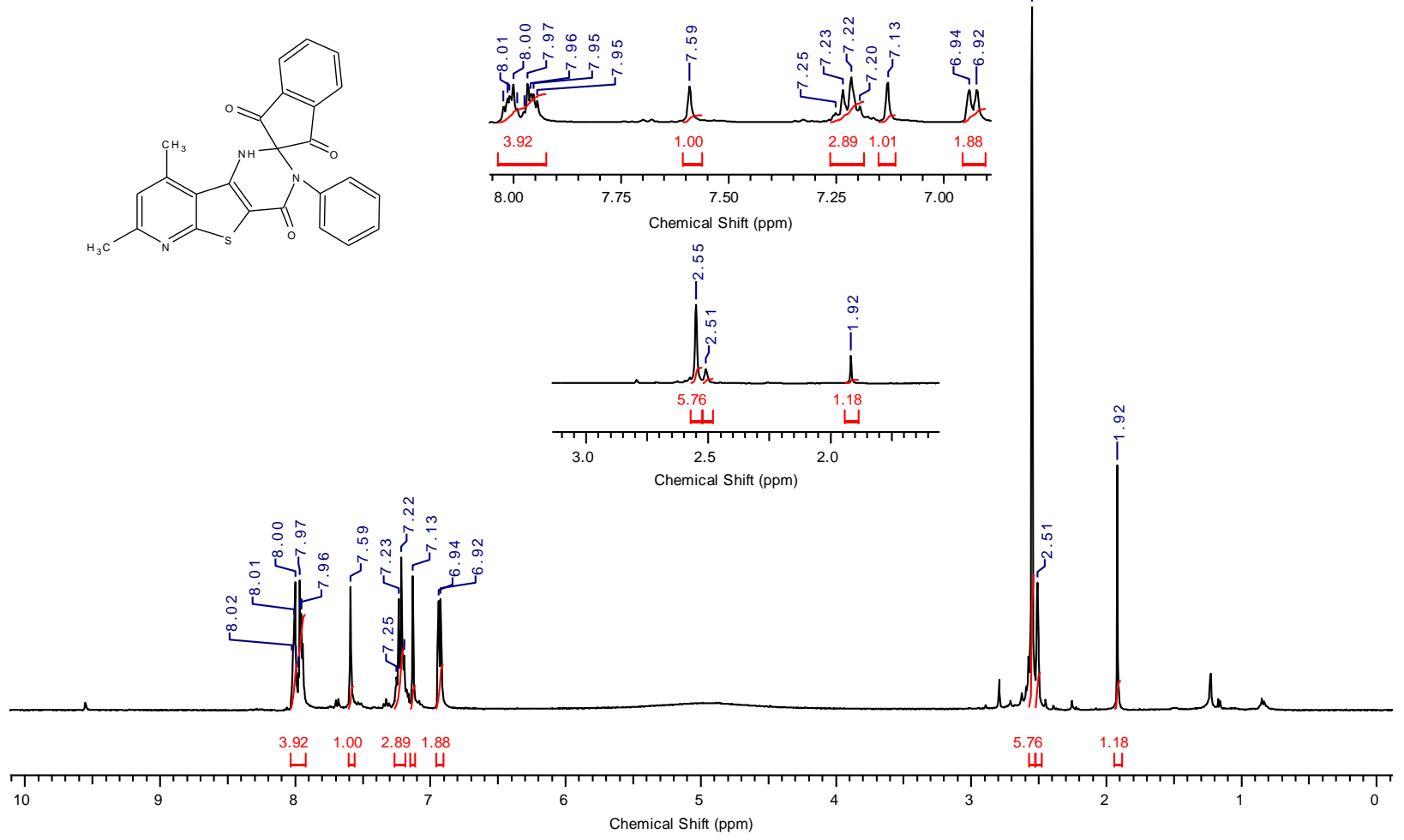

\section{References}

1. Kul'nevich V. G. et al. Synthesis and anti-viral activity of N-alkyl-3-cyano-2pyridones and 3-cyano-2-alkoxypyridines // Pharm. Chem. J. - 1990. - Vol. 24. - No 2. - pp. 132-135.

2. Guerrera F., Siracusa M. A., Tornetta B. Synthesis of 3-aminothieno-(2, 3-b) pyridine derivatives. II // Il Farmaco Ed.Sci. - 1976. - Vol. 31. - No 1. - pp. 2130.

3. A. M. Shestopalov, K. G. Nikishin, A. V. Gromova, and L. A. Rodinovskaya. One-pot synthesis of 4,6-diaryl-3-cyanopyridine-2(1H)-thiones and their transformation to substituted thieno[2,3-b;4,5-b]dipyridines and pyrido[3',2':4,5]thieno[3,2-d ]pyrimidines // Russ. Chem. Bull., Int Ed. - 2003. - Vol. 52. - No. 10. - Pp. 2203-2206. 